\title{
Spectrum of reproductive health problems for which adolescent girls seek consultation in hospital based adolescent clinic
}

\author{
Mudita Jain, Jyoti Nath Modi*
}

\author{
Department of Obstetrics \& Gynaecology, People's College of Medical Sciences\& Research Centre, Bhopal, MP, \\ India
}

Received: 05 October 2015

Accepted: 23 October 2015

\author{
*Correspondence: \\ Dr. Jyoti Nath Modi, \\ E-mail: modijn@gmail.com
}

Copyright: $\odot$ the author(s), publisher and licensee Medip Academy. This is an open-access article distributed under the terms of the Creative Commons Attribution Non-Commercial License, which permits unrestricted non-commercial use, distribution, and reproduction in any medium, provided the original work is properly cited.

\begin{abstract}
Background: Adolescent girls in India are usually shy and hesitant in discussing reproductive health issues. Gradually this trend is changing with more adolescent girls seeking consultation in hospitals for these issues. The purpose of the present study was to analyze the reproductive health problems for which adolescent girls seek consultation in the adolescent clinic of Gynaecology department at a medical college hospital.

Methods: A retrospective analysis of Adolescent clinic records was carried out at a medical college hospital in central India. The Gynaecology outpatient based Adolescent clinic records were analyzed for the presenting symptoms of girls attending this clinic over a period of two years (1st January 2013 to 31st December 2014).

Results: A total of 1541 adolescent girls sought care in the Adolescent clinic of the Gynecology over the two year period. Of these, the majority consulted for menstrual irregularity (31\%). The other reason for consultation was pain abdomen $(18.8 \%)$, white discharge per vaginum (10.7\%), dysmenorrhea (8.6\%), urinary symptoms $(5.6 \%)$, etc.

Conclusions: The predominant health concern for which the adolescent girls seek consultation in hospital is menstrual irregularity besides dysmenorrhea and white discharge. Many of these issues can be addressed in adolescent school health education programs and may help alleviate the anxiety of young girls.
\end{abstract}

Keywords: Adolescent girls, Menstrual irregularity, Dysmenorrhea, Menorrhagia, Vaginal discharge

\section{INTRODUCTION}

Adolescence is marked by many physical as well as psychosocial transformations. Onset of menarche is a predominant physiological change that requires physical, psychological as well as social adjustment by the young girls. In the initial years following menarche, many girls encounter irregularity in menses, dysmenorrhoea or other physical problems such as acne, weight gain, etc. for which they may consult family (mother, elder sister or other female relative) or sometimes, the doctor. There has been a reluctance of girls as well as their mothers towards seeking help for reproductive health issues during adolescent years. ${ }^{1}$ Fortunately, this scenario is changing now, and increasingly, the adolescent girls are approaching heath care facilities for addressing their reproductive health concerns. ${ }^{2}$

According to the 2011 census, nearly $21 \%$ of India's population is in the adolescent age group of 10-19 years totalling to a 253 million adolescents. ${ }^{3}$ Adolescents are the resources for the future of any nation and hence their health and wellbeing is of paramount importance. Among the health issues also, the reproductive and sexual health issues merit priority since this age group has a distinct set of reproductive health issues that need to be addressed in a timely manner. ${ }^{4}$ Reproductive health problems at this age have the potential of affecting the future fertility as well. Adolescent girls in India have traditionally been shy and hesitant in discussing the reproductive and sexual 
health problems and concerns. This further leads to social problems, absence from school and at times, hampering of daily activity.

It would be informative to know the predominant issues that bring these young girls to hospital. Our hospital is a tertiary care medical college hospital receiving patients from nearby districts. It is important to know the frequency, pattern of and various presentations for which adolescent are reporting in outdoor. This in turn will help to develop strategies for patient counselling and development of regular school health programs, along with special adolescent clinics to address their problems.

\section{METHODS}

This retrospective analytical study was carried out in the Department of Obstetrics and Gynaecology of Peoples College of Medical Sciences \& Research Centre, Bhopal. The data from the Adolescent clinic located in the Gynaecology outpatient was analyzed over a 2 year period i.e. $1^{\text {st }}$ January $2013-31^{\text {st }}$ December 2014 , for the presenting symptoms of the girls seeking consultation.

Inclusion criteria: The clinic records of all the girls between the ages 10 to 19 years who attended the Adolescent clinic (except one girl aged 8 years who attended the clinic for precocious puberty), in this time period were included in the study. The data was analyzed by descriptive statistics using MS Excel spreadsheet.

\section{RESULTS}

A total of 1541 adolescent girls in the age range 10 years to 19 years (except 1 girl of age 8 years) attended the clinic in this two-year period. The reproductive health issues for which these girls sought consultation are shown in Table 1. The majority of girls (nearly one third; 477/1541) sought consultation for irregularity in menstrual cycles. Of these, 63 girls $(4.1 \%)$ were already diagnosed with Polycystic Ovarian Syndrome. The next common complaint was pain abdomen (18.8\%) followed by concern about white discharge per vaginum $(165 / 1541 ; 10.7 \%)$ and dysmenorrhoea $(8.6 \%)$ (Figure 1).

Overall, $103(6.7 \%)$ girls presented with menorrhagia. Of these, 32 were in the early years after menarche and were labeled as puberty menorrhagia for the purpose of analysis. Urinary symptoms were another problem for which the young girls sought consultation. Forty-Eight adolescents presented with pregnancy related issues. This number is besides those registering directly in the Antenatal clinic. Though very few, some married adolescents also sought consultation for infertility $(11 / 1541 ; 0.7 \%)$. Primary amenorrhea was the presenting symptom of 34 girls (2.2\%). Lump abdomen, pruritus vulvae, mastalgia and breast lump were some other health issues that the girls presented with. Forty two girls had presented for a routine health checkup.
Table 1: Reproductive health problems for which the adolescent girls sought consultation in adolescent clinic of gynaecology department.

\begin{tabular}{|lll|}
\hline $\begin{array}{l}\text { Presenting } \\
\text { complaint/problem }\end{array}$ & $\begin{array}{l}\text { No of girls } \\
(\mathbf{N}=1541)\end{array}$ & Percentage \\
\hline $\begin{array}{l}\text { Menstrual } \text { [of which } \\
\text { irregularity }\end{array}$ & $\begin{array}{l}\text { 63 were } \\
\text { pre-diagnosed } \\
\text { PCOS] }\end{array}$ & $31 \%$ \\
\hline Pain abdomen & 290 & $18.81 \%$ \\
\hline $\begin{array}{l}\text { White discharge per } \\
\text { vaginum }\end{array}$ & 165 & $10.70 \%$ \\
\hline Dysmenorrhoea & 132 & $8.57 \%$ \\
\hline UTI & 86 & $5.58 \%$ \\
\hline Menorrhagia & 71 & $4.61 \%$ \\
\hline PCOS & 63 & $4.08 \%$ \\
\hline Obstetric causes & 48 & $3.11 \%$ \\
\hline Routine check up & 42 & $2.72 \%$ \\
\hline Prim amenorrhoea & 34 & $2.21 \%$ \\
\hline $\begin{array}{l}\text { Puberty } \\
\text { menorrhagia }\end{array}$ & 32 & $2.08 \%$ \\
\hline Pruritus vulvae & 17 & $1.10 \%$ \\
\hline Mastalgia & 25 & $1.62 \%$ \\
\hline Lump Breast & 23 & $1.5 \%$ \\
\hline Primary infertility & 11 & $0.71 \%$ \\
\hline Lump abdomen & 10 & $0.65 \%$ \\
\hline Medical reasons & 9 & $0.58 \%$ \\
\hline Delayed puberty & 4 & $0.26 \%$ \\
\hline $\begin{array}{l}\text { Secondary } \\
\text { amenorrhoea }\end{array}$ & 1 & $0.065 \%$ \\
\hline Precocious puberty & 1 & \\
\hline & & \\
\hline
\end{tabular}

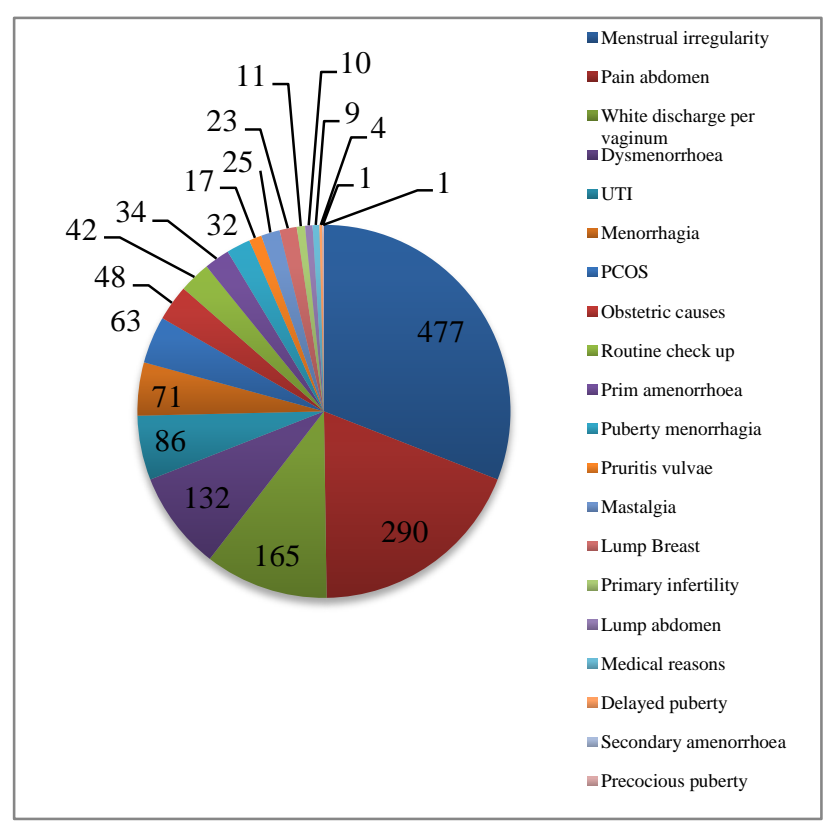

Figure 1: Presenting symptoms/reproductive health problems of adolescent girls attending the adolescent clinic of gynaecology department from January 2013 to December $2014(\mathrm{~N}=1541)$. 


\section{DISCUSSION}

In our study menstrual irregularity was found in $31 \%$ of girls presenting to the Gynaecology department Adolescent clinic. The study from Nagpur by Kulkarni et al reported $65 \%$ of girls with one or more reproductive problem, menorrhagia being a complaint in $16 \%$ of girls. ${ }^{1}$ The studies from Hong Kong by Chan et al. and Chung et al. found it to be much higher i.e. $58 \%$ and $47 \%$ respectively. ${ }^{5,6}$ This difference may reflect the difference in education or awareness level and the health seeking behavior that varies with culture.

The occurrence of dysmenorrhea was $8.6 \%$ in our study, which is similar to that reported by Chan et al in 2009.5 However, a higher prevalence had been reported in the studies by Sharma et al. (33\%), Nag (33.8\%), and Singh et al. $(40.7 \%) .^{7-9}$ The study from Nagpur by Kulkarni et al in 2012 reported dysmenorrhoea to be the most common reproductive health problem occuring in nearly $54 \%$ of girls and backache during menses in $42 \%$ girls. ${ }^{1}$ This low reporting of dysmennorhea can be attributed to the girls either coping well or managing the problems using over the conter medications/ home remedies or the other major factor can be their failure to visit gynaec outdoors either due to hesitancy or family taboos .

Another symptom that bothered the girls of this age was white discharge per vaginum, reported by $10.7 \%$ of the girls in the present study. It was similar to that reported by b. We found primary amenorrhea to be present in $2.2 \%$ girls. This was similar to $3 \%$ prevalence reported by Chung et al. ${ }^{6}$ Kulkarni et al reported a lower frequency of this problem $(5.4 \%)$ though Joshi et. al. report it as $21 \%$. $^{1,2}$

Urinary complaints were reported by $17 \%$ in the study by Joshi et al but we found it to be only about 5.6\%. ${ }^{2}$ Though only 48 adolescents had reported with pregnancy or related problems to the adolescent clinic, this would be an underestimate of the burden of adolescent pregnancy in our setting. Many adolescents would be reporting directly to the Antenatal clinic of the department rather than to the adolescent clinic. The National Family Health Survey I, II, and III data show a consistence rise in the percentage of first pregnancy among adolescents: $11.7 \%, 12.4 \%$ and $14.4 \%$ respectively. ${ }^{10}$

Overall the spectrum of problems for which the adolescent girls seek consultation in hospitals is similar to that reported in other studies though the frequency of individual problems may vary due to geographical, cultural and ethnic reasons. ${ }^{1,2,5,6}$

Many of the problems for which the adolescent seek consultation require counseling and advisory rather than pharmacologic treatment. Menstrual irregularity is a major reason for consultation and many girls in the initial 1-2 years of menarche only need to be reassured. Similarly the girls complaining of white discharge need to be counseled regarding the physiological vaginal discharge and the infective one. Pain abdomen and dysmenorrhea can be disabling and interfere with daily activities, hence should be addressed accordingly with prescription for appropriate analgesics.

\section{CONCLUSIONS}

In this paper, an attempt was made to study the pattern of self-reported reproductive health problems in a hospital based adolescent clinic. The spectrum as well as magnitude of problems encountered in the community may vary. The most frequent morbidity was menstrual problems (irregularity, menorrhagia) followed by lower abdominal pain, dysmenorrhoea and vaginal discharge. Some issues may also be addressed if regular school health programs, along with special school based adolescent clinics to address their problems are instituted.

\section{ACKNOWLEDGEMENTS}

We gratefully acknowledge the contribution of postgraduate students of the department of Obstetrics \& Gynaecology of our institute in maintaining documentation in the Adolescent clinic.

Funding: No funding sources

Conflict of interest: None declared

Ethical approval: The study was approved by the Institutional Ethics Committee

\section{REFERENCES}

1. Kulkarni MV, Durge PM. Reproductive health morbidities among adoelscent girls: breaking the silence. Ethno Med. 2011;5(3):165-8.

2. Joshi BN, Chauhan SL, Donde UM, Tryambake VH, Gaikwad NS, Bhadoriya V. Reproductive health problems and help seeking behavior among adolescents in urban India. Indian $J$ Pediatr. 2006;73:509-13.

3. Government of India. Census of India. Registrar General of India. 2011. Available from: http://www.censusindia.gov.in.

4. Nath A, Garg S. Adolescent friendly health services in India: A need of the hour. Indian $\mathrm{J}$ Med Sci. 2008;62(11):465-72.

5. Chan SS, Yiu KW, Yuen PM, Sahota DS, Chung TK Menstrual problems \& health seeking behaviour in Hongkong Chinese girls. Hongkong Med J. 2009;15(1):18-23.

6. Chung PW, Chan SS, Yiu KW, Lao TH, Chung TK. Menstrual disorders in a pediatric \& adolescent gynecology clinical patient presentation \& longitudinal outcome. Hongkong Med J. 2011;17(5):391-7.

7. Sharma A, Taneja DK, Sharma P, Saha R. Problems related to menstruation and their effect on daily routine of students of a medical college in Delhi, India. Asia Pac J Public Health. 2008;20(3):234-41. 
8. Nag RM. Adolescent in India. Calcutta: Medical Allied Agency. 1982:18-26.

9. Singh MM, Devi R, Gupta SS. Awareness and health seeking behaviour of rural adolescent school girls on menstrual and reproductive health problems. Indian $\mathbf{J}$ Med Sci. 1999;53(10):439-43.

10. Sivagurunathan C, Umadevi R, Gopalakrishnan. Adolescent health: Present status Present status and its related programmes in India. Are we in the right direction? Journal of Clinical and Diagnostic Research. 2015;9(3):LE01-6.

Cite this article as: Jain M, Modi JN. Spectrum of reproductive health problems for which adolescent girls seek consultation in hospital based adolescent clinic. Int J Reprod Contracept Obstet Gynecol 2015;4:1700-3. 